\title{
Construction of Regional Logistics Information Platform Based on Cloud Computing
}

\author{
Gang SUN ${ }^{1,2, a,{ }^{*}, \text { Xiu-You WANG }}{ }^{1, b}$, Hao WANG ${ }^{1, c}$ and Jia ZHAO ${ }^{1, d}$ \\ ${ }^{1}$ School of Computer and Information Engineering, Fuyang Teachers College, Fuyang, China \\ ${ }^{2}$ Data Mining and Intelligent Computing Laboratory, Hefei University of Technology, Hefei, China \\ aahfysungang@163.com, bwangxiuyou@163.com, ahseal@163.com, \\ dzhaojia11b@mails.ucas.ac.cn
}

Keywords: Regional logistics, Cloud computing, Information platform

\begin{abstract}
Regional logistics information platform based on cloud computing is the development direction of regional logistics information platform in the future. In this paper, the target, design principles, network topology, logical structure and architecture of regional logistics information platform based on cloud computing are studied on the basis of analyzing and researching cloud computing and Hadoop technology. It provides technical support for construction of regional logistics information platform based on cloud computing.
\end{abstract}

\section{Introduction}

Regional logistics information platform is neural networks of regional logistics, linking to each level and each aspect of logistics system. It is an important part of regional logistics information, as well as an important way of promoting modern logistics industry development by local government. Regional logistics information platform is essentially an integrated management information system, which integrate regional logistics information resources through the use of modern information technology and communication technology, and effectively manage planning, coordination, implementation and monitoring of supply chain[1,2]. Cloud computing is a new business model, which allows users to access computing power, storage space and information services according to their demand[3]. Construction of regional logistics information platform based on cloud computing will contribute to integrating logistics resources, reducing logistics costs and improving logistics efficiency, and it provides information technical support for the rapid development of regional logistics.

\section{Cloud Computing}

\section{The Concept of Cloud Computing}

Cloud computing is an advanced technology, which is the results of comprehensive development of parallel computing, distributed computing and grid computing. It manages computers distributed in different places, and it has a powerful computing capability and massive storage capacity to satisfy the various needs of different types of applications[4]. Cloud computing has some characteristics with data secure, shareable, scalability, large-scale and low price and so on. According to different services, cloud computing has 3 models: SaaS (software as a service), PaaS (platform as a service) and IaaS (infrastructure as a service). Cloud computing service model is shown in Figure 1. Cloud computing is data-centric, and it has a unique technology in parallel data processing, programming model and virtualization and so on. 


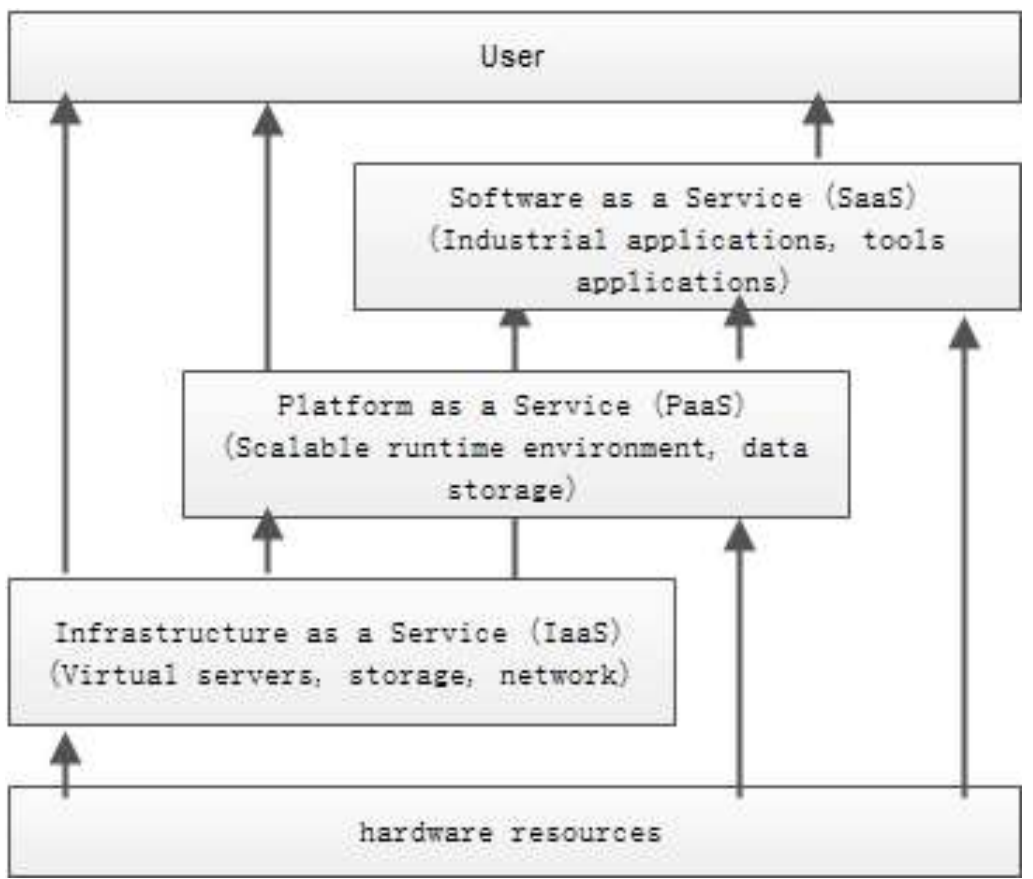

Fig. 1 Cloud computing service model

\section{Hadoop Technology}

Hadoop is open-source distributed computing framework developed by Apache Foundation organization. It uses inexpensive computing equipment to build a large computing pool in order to improve the speed and efficiency of analyzing massive data. It is low-cost cloud computing solution[5]. Hadoop technology provides a relatively simple, easy-to-program interface, therefore, it is a distributed computer platform easily handling and storing large amounts of data. It has some characteristics with strong expansibility, low cost, higher efficiency and better security and so on.

Hadoop is a collection of related sub-project, the core of which is Hadoop Common, HDFS and MapReduce, and other subprojects of which provide complementary services. Hadoop technology stack is shown in Figure 2.

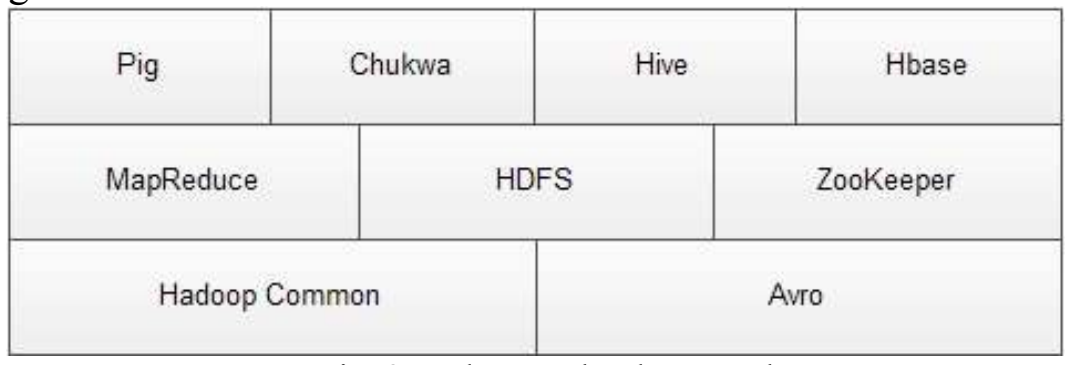

Fig. 2 Hadoop technology stack

\section{Regional Logistics Information Platform Based on Cloud Computing}

\section{Target and Principles of Construction}

The target of constructing regional logistics information platform based on cloud computing is to use a number of low-end PC servers to set up Hadoop cloud computing platform, and to support analysis demand of massive logistics data, and to improve the speed and efficiency of data analysis, and to provide immediate and accurate information services for business decisions, meanwhile, to save the investment cost for regional logistics information construction[6].

Principles of constructing platform include: economic principle, efficient principle, and security principle. Economic principle: It takes full use of existing resources to build the infrastructure of platform. According to Hadoop less demanding on the hardware, it uses a number of low-end PC servers to set up Hadoop clusters. Efficient principle: It uses the advantage of cloud computing 
platform to improve the efficiency of process massive logistics data. Security principle: In the process of constructing platform, the own safety of platform and information security are fully considered. The necessary measures are taken to avoid the security risks.

\section{Network Topology Structure of Platform}

Network topology structure of regional logistic information platform based on cloud computing includes front-end operating area and back-end production area[7], and the production area includes Hadoop clusters LAN and various servers. The network topology structure is shown in Figure 3.

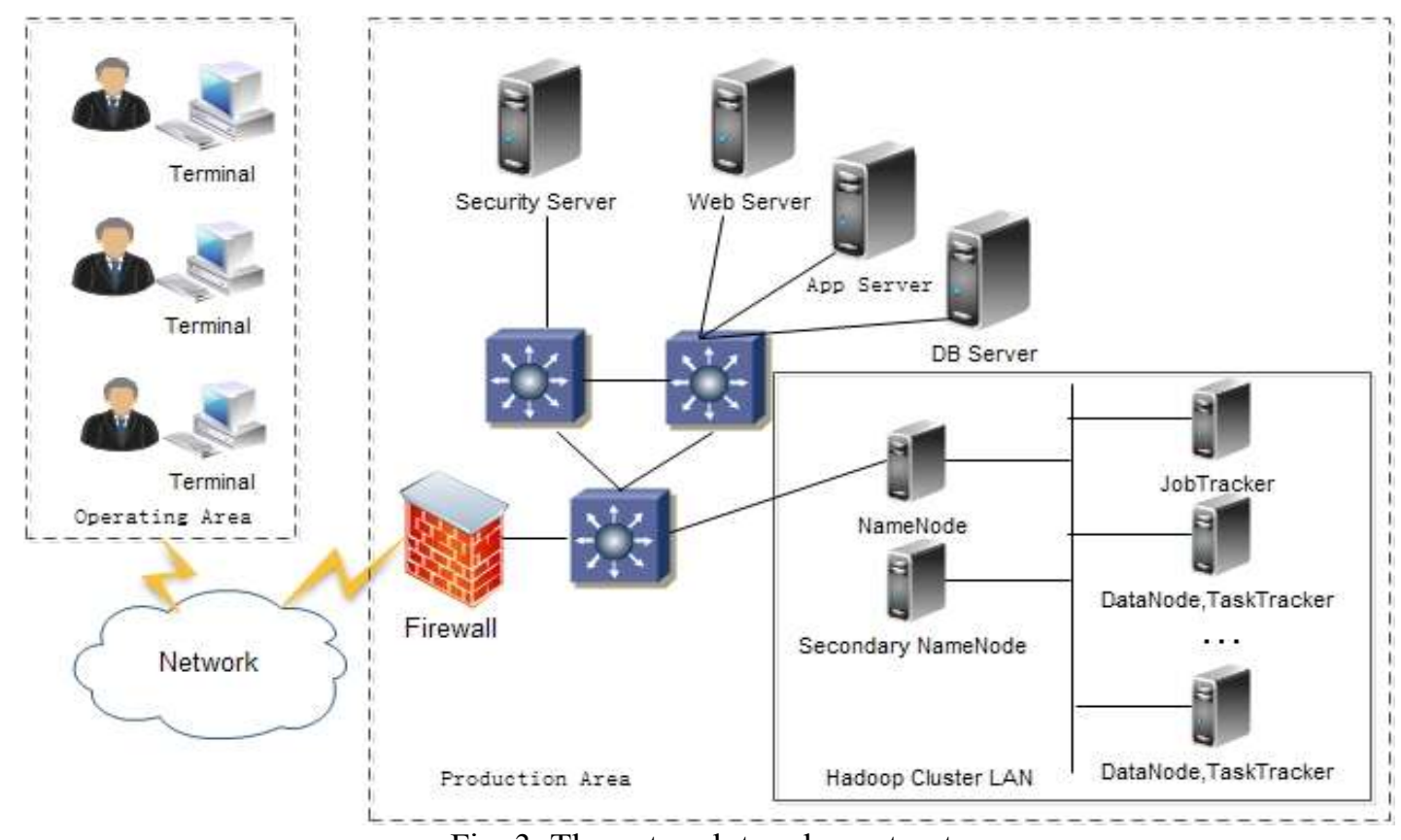

Fig. 3. The network topology structure

Hadoop clusters LAN consists of 1 NameNode server, 1 secondary NameNode server, a JobTracker server and several secondary servers.

NameNode server is responsible for managing the segmentation and storage of massive data files, and monitoring the operating conditions of DataNodes. Application needs to read the data files, it firstly visits NameNode server to access to data files distributed on DataNodes, and then it communicates directly with DataNode. Once a DataNode is down, NameNode will notify the application to access the copy of each data block of the DataNode, and adds the copy of each data block on other DataNodes, in order to ensure reliable operation of the platform.

Secondary NameNode server is responsible for monitoring HDFS state, and communicates with NameNode to save regularly a snapshot of HDFS metadata. If NameNode fails, it is used as a standby NameNode.

JobTracker server is responsible for managing the decomposition and summary of computing task, and monitors the operation condition of each TaskTracker. Once a task fails, JobTracker automatically restarts the task.

Secondary sever has both roles of DataNode and TaskTracker. It is responsible for the data blocks storage and the data blocks calculation respectively.

\section{Logic Model of Platform}

Typical cloud computing services includes three models[8]. IaaS: It provides the infrastructure (computing power, storage capacity, network resource) as a service to users, and users get virtual server according to their own demand. PaaS: It provides API or development platform for users to create their own applications in the cloud, and users do not need to focus on the bottom cloud infrastructure. SaaS: It provides various applications running on cloud infrastructure for users, and users can access these applications through the client interface. 
On the basis of in-depth analysis of regional logistics service resources, job tasks and related supporting technology, the logical model of regional logistics information platform based on cloud computing is built. The logical model of platform mainly consists of cloud service provider, cloud service management platform and cloud service receiver[9]. Cloud service provider mainly provides basic logistics services, such as warehousing, transportation, production, distribution and customs, etc., which is carrier of the different logistics resources and service resources managed and organized by cloud service management platform. Cloud service management platform is responsible for abstraction, integration, scheduling and matches of logistics service resources, and it provides real-time and personalized logistics services for cloud service receiver. Cloud service receiver is mainly user of cloud logistics services, facing various operating entities and the corresponding customers. The logical model of regional logistics information platform based on cloud computing is shown in Figure 4.

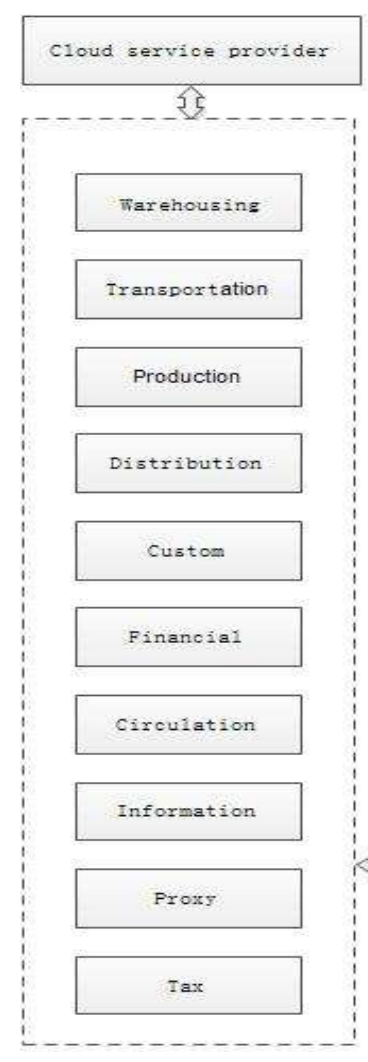

\section{System Architecture of Platform}

On the basis of the logical model of regional logistics information platform based on cloud computing, the system architecture of regional logistics information platform based on cloud computing is set up through further analyzing and refining structure and application of platform. The system architecture of platform consists mainly of IaaS, PaaS, SaaS and client, which is designed by using service-oriented architecture and using web services description language to describe service interfaces[10]. IaaS model provides cloud access and sharing of basic logistics service resources of regional logistics. PaaS model provides convenient Web services for users of regional logistics. SaaS model provides software services for all kinds of logistics service entities in regional logistics area. Client accesses cloud service interface of regional logistics job tasks, and provides on-demand service requests. Finally, the services sharing and resources allocation platform of regional logistics based on cloud computing is set up, which implement new regional logistics service model and optimize the allocation of logistics service resources. The system architecture of regional logistics information platform based on cloud computing is shown in Figure 5. 


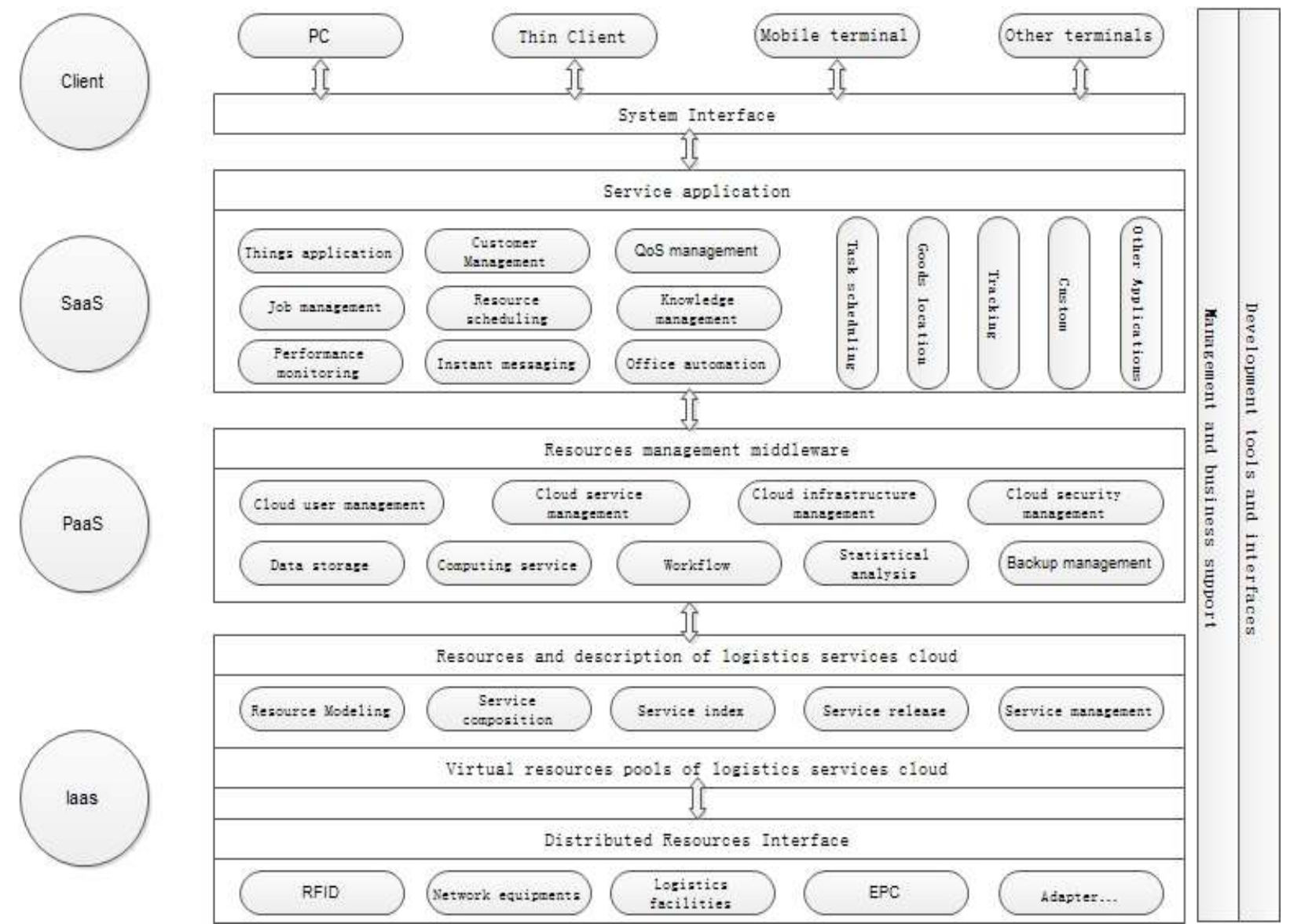

Fig. 5. The system architecture

\section{Conclusions}

Regional logistics information platform based on cloud computing is the key and core of regional logistics information, and it is also the objective need of regional logistics development. Regional logistics information platform based on cloud computing is the development direction of regional logistics information platform in the future. The target, design principles, network topology, logical structure and architecture of regional logistics information platform based on cloud computing are studied in this paper. It provides a guideline and reference for the construction of logistics information platform, and it has some practical needs and application values.

\section{Acknowledgement}

The work was supported by the National Natural Science Foundation of China(51174257 /F0305 04), and supported by the Fundamental Research Funds for the Central Universities of Hefei University of Technology (2013BHZX0040), and supported by special key project funds commissioned by Anhui Province-level research institution(2013WLGH01ZD).

\section{References}

[1] Wang Jian, Mao Haijun, Hua Wenjing. City Logistics Information Platform [J]. Journal of Transport Information and Safety,2004,22(5): 79-82.

[2] Duan Zhengyu, Sun Wei, Chen Chuan. Research on Logistics Information Platform Planning of Regional Central Cities [J]. Logistics Science and Technology,2009,32(2):50-53.

[3] Liu Peng. Cloud Computing[M]. Beijing: Publishing House of Electronics Industry, 2010. 
[4] Wang Peng. Key Technology and Application Examples of Cloud Computing [M]. Beijing: Posts and Telecom Press, 2010.

[5] Liu Peng. Hadoop in Pratice [M]. Beijing: Publishing House of Electronics Industry, 2011.

[6] Wang Dewen, Song Yaqi, Zhu Yongli. Information Platform of Smart Grid Based on Cloud Computing [J] Automation of Electric Power Systems,2010,34 (22):7-12.

[7] LI Hongjian, Liu Heng, Huang Guangwen. Study on Massive Telecom Data Cloud Computing Platform Based on Hadoop [J]. Telecommunications Science,2012,28(8):80-85.

[8] Qin Xiaoli, Luo Wei, Li Yuping. Design Cloud-based Information Service Platform for Tropical Agricult [J]. Guangdong Agricultural Sciences,2014,41(19):188-193.

[9] Dong Qianli. Regional Logistics Information Platform and Resource Planning [J]. Journal of Traffic and Transportation Engineering,2002,2(4): 58-62.

[10]Zhang Hao, Hong Qiong, Zhao Gang. Research of Logistics Park Service Resource Sharing and Configuration Mode based on Cloud Logistics Services [J]. Application Research of Computers, 2014, 31(2):476-479. 